\title{
Assessment of Factors Affecting Social Insurance Management by Analytic Hierarchy Process Method:
}

\author{
A Case in Vietnam
}

\author{
Phan-Anh-Huy Nguyen* \\ Faculty of Economics \\ HCMC University of Technology and Education \\ Ho Chi Minh city, Vietnam \\ *huynpa@hcmute.edu.vn
}

\author{
Thi-Hong-Tham Nguyen \\ Faculty of Economics \\ HCMC University of Technology and Education \\ Ho Chi Minh city, Vietnam \\ hongtham070684@gmail.com
}

\begin{abstract}
The purpose of this study is to evaluate the factors affecting the management of social insurance collection in Tien Giang province in Vietnam by Analytic Hierarchy Process (AHP) method. This study surveyed the opinions of 12 experts in this field including managers and chief accountants. The research results show the differentiation in the importance of the criteria for evaluating the factors affecting the management of social insurance management. The AHP analytic results show that the criteria are arranged according to the weights of priority from high to low as follows: Qualification of staff in charge of social insurance collection management, Labour and employment policy, Salary policy, Inspection, and inspection work. The implication of this study could support the policy makers in social insurance collection management.
\end{abstract}

Keywords-AHP, social insurance, labor policy, salary policy, employment policy

\section{INTRODUCTION}

While the industrial revolution 4.0 is taking place in many countries around the world as well as Vietnam, the risks such as illness, accident labour, occupational disease, maternity, job loss are happening more and more frequently. When these risks occur, it will cause difficulties for employees both physically and mentally and negatively affecting the whole community. Social insurance has contributed to help individuals who are exposed to risks and misfortunes by creating alternative incomes, favourable working conditions to stabilize their lives. Thus, it contributes significantly to the increase of labour productivity as well as the quality of work for businesses in particular and for the whole society in general. The collection of social insurance, health insurance and unemployment insurance play a very important role and is decisive to the implementation of the political tasks of the social insurance industry.

In some development countries, many enterprises have not participated in social insurance and health insurance for their employees, the collection of social insurance, health insurance and unemployment insurance are still difficult and problematic.
Although there have been many solutions such as propaganda, inspection, assessment, and transferring documents to the authorities to request criminal handling. However, the debt and late payment of social insurance are still there. The collection of social insurance is facing many difficulties because not only is it difficult to correctly grasp the data of people participating in social insurance. Furthermore, many employers do not pay attention to social insurance policy, find ways to circumvent the law. Therefore, the management of social insurance collection meets many difficulties. Although there are some researches related to social insurance, but none of them using investigate factors affecting social insurance management. To have suitable policies and measures to strengthen the management of social insurance collection to ensure the benefits of workers, this paper aims to evaluate the factors affecting the management of social insurance collection in Tien Giang province in Vietnam by Analytic Hierarchy Process (AHP) method. Then, the managerial implications are proposed to support the policy makers in social insurance collection management.

\section{LITERATURE REVIEW}

There are some studies related to social insurance collection in recent years. Ansari et al [1] decentralizes the management of social insurance collection using the SPSS regression model with 7 observed variables to evaluate the factors affecting the decentralization. management of social insurance collection in India. The author also gives a research model and implications of governance in the management of social insurance collection, but the author's research is based on the research data of decentralized collection management without specific assessment. According to Andreas and Anastasion [2], on the basis of studying 5 models of factors affecting collection of social insurance and social security, the author has clarified a number of concepts around the issue of social insurance collection, the situation of collection management. Social insurance in European countries in the years 2008 - 2013. The author also evaluated social insurance collection tools of countries such as UK, France, Germany. Nguyen Thi Mai [3] 
investigated on the basis of researching experience in social insurance collection management of some countries around the world and summarizing the practical activities of social insurance collection management in Vietnam and Ha Giang province in the period 2010 - 2015 ; The author clarifies the current situation of social insurance activities, especially the collection of social insurance in recent years, in order to analyse the ability to collect social insurance to offset the social insurance spending regimes, gradually replace the sources of spending from the State budget. At the same time, proposing a number of specific recommendations to improve the collection of social insurance in Vietnam in general and Ha Giang province in particular. Tran Van Hung [4] conducted a research of 5 models of social insurance collection management of countries in the region and the world, the author has clarified a number of concepts around the issue of social insurance collection, evaluating the factors affects the management of social insurance collection in Cam My district, Dong Nai province. Do Van Sinh [5] studied the situation of outstanding debts and evasion of social insurance contributions in Vietnam during 2010-2015. The author also offers methods to manage the social insurance fund and proposes solutions and recommendations to limit the situation of outstanding debts and evasion of social insurance contributions in the coming time for Vietnam

These studies have provided a theoretical basis for the management of social insurance revenues and expenditures in different angles and locations, through the evaluation of the factors affecting the collection of social insurance by a linear regression model. However, there are no studies assessing the factors affecting the collection of social insurance by AHP approach in Tien Giang province.

\section{RESEARCH METHODOLOGY}

\section{A. AHP Method}

Thomas L. Saaty [6] developed a decision-making method known as the Analytic Hierarchy Process (AHP) to help handling complex multi-standard decision-making problems. The AHP methodology allows decision-makers to gather the knowledge and experience of experts in their fields to combine objective and subjective data in a logical hierarchical framework. The AHP method provides decision-makers with a visual approach to assess the importance of each criterion through a pairwise comparison process. AHP can support both qualitative and quantitative analysis. Qualitative Through the hierarchy and quantitative through the description of the ratings and the preference for the numbers can be used to describe the expert's judgments. AHP is based on 3 principles: (i) Analysing decision-making problem (setting hierarchy), (ii) Evaluating and comparing criteria, (iii) Synthesizing priorities.

The scale is from 1 to 9 as shown in table 1 . In which $a_{i j}$ is the evaluation level between the $i^{\text {th }}$ alternative compared to the $\mathrm{j}^{\text {th }}$ alternative, with $\mathrm{a}_{\mathrm{ij}}>0, \mathrm{a}_{\mathrm{ij}}=1 / \mathrm{a}_{\mathrm{ji}}, \mathrm{a}_{\mathrm{ii}}=1$.

TABLE I. WEIGHT MATRIX

\begin{tabular}{|c|c|c|c|c|c|}
\hline & a1 & a2 & a3 & a4 & a5 \\
\hline a1 & w11 & w12 & w13 & w14 & w15 \\
\hline a2 & w21 & w22 & w23 & w24 & w25 \\
\hline a3 & w31 & w32 & w33 & w34 & w35 \\
\hline a4 & w41 & w42 & w43 & w44 & w45 \\
\hline a5 & w51 & w52 & w53 & w54 & w55 \\
\hline
\end{tabular}

Let $\mathrm{w}_{\mathrm{ii}}$ be the important element of the element, $\mathrm{W}_{\mathrm{ii}}$ is calculated by the following formula:

$$
w_{i i}=\frac{a_{i i}}{\sum_{i=1}^{n} a_{i n}}
$$

The consistency ratio of the experts can be determined by the consistency ratio $(\mathrm{CR})$ :

$$
C R=\frac{C I}{R I}
$$

CI: Consistency Index

$$
C I=\frac{\lambda_{\max }-n}{n-1}
$$

RI: the random index (Random Index). RI is determined from the given table 2 .

$\lambda \max$ : eigenvalue of the comparison matrix

$\mathrm{n}$ : number of factors

TABLE II. RANDOM INDEX FOR THE NUMBER OF FACTORS (RI)

\begin{tabular}{|c|c|c|c|c|c|c|c|c|c|c|c|c|c|c|c|}
\hline $\mathbf{n}$ & $\mathbf{1}$ & $\mathbf{2}$ & $\mathbf{3}$ & $\mathbf{4}$ & $\mathbf{5}$ & $\mathbf{6}$ & $\mathbf{7}$ & $\mathbf{8}$ & $\mathbf{9}$ & $\mathbf{1 0}$ & $\mathbf{1 1}$ & $\mathbf{1 2}$ & $\mathbf{1 3}$ & $\mathbf{1 4}$ & $\mathbf{1 5}$ \\
\hline $\mathrm{RI}$ & 0.00 & 0.00 & 0.58 & 0.90 & 1.12 & 1.24 & 1.32 & 1.41 & 1.45 & 1.49 & 1.51 & 1.48 & 1.56 & 1.57 & 1.59 \\
\hline
\end{tabular}

The AHP method checks the consistency through the consistency ratio (CR), the value of the best consistency ratio is less than $10 \%$, if greater, the judgment is not stable, it should be evaluated again.

\section{B. Influencing factors}

The influencing factors are inherited from previous studies in the field of social insurance such as Do Van Sinh [5] and Pham Thi Hoa [7]. Based on the actual situation of the collection of social insurance and health insurance of the Social Insurance of Tien Giang Province from the perspective of the Board of Directors and experts in the field of social insurance, this study proposes four basic elements. Include (1) Salary policy; (2) Labour and employment policy; (3) Qualification of staff in charge of social insurance collection management; (4) The inspection and assessment of the implementation of the law on social insurance affect the management of social insurance. According to experts, the selection of basic factors will reduce the complexity in evaluating and proposing their 
views as well as reducing the complexity in calculating and processing statistics (table 3 ).

TABLE III. VARIABLES IN THE RESEARCH MODEL

\begin{tabular}{|l|l|}
\hline \multicolumn{1}{|c|}{ Influencing Factors } & Variables \\
\hline Salary policy & CSL \\
\hline Labor and employment policy & LDVL \\
\hline $\begin{array}{l}\text { Qualification of staff in charge of social insurance } \\
\text { collection management }\end{array}$ & TĐCB \\
\hline $\begin{array}{l}\text { The inspection and assessment of the implementation of } \\
\text { the law on social insurance }\end{array}$ & TTKT \\
\hline
\end{tabular}

\section{Data Collection}

This research conducted in-depth interviews with 5 experts in the fields of accounting, IT, and finance. the nature of the process of collection and spending of health insurance is the chief accountant of social insurance of Tien Giang province; 6 people work as accountant of revenue and expenditure of health insurance at Vietnam Social Insurance. Through indepth interviews combined with theoretical knowledge, the study finds research gaps in revenue management (table 4).

TABLE IV. IMPORTANCE OF SCALES [6]

\begin{tabular}{|l|l|}
\hline Scales & \multicolumn{1}{|c|}{ Linguistics values } \\
\hline 1 & Equivalent importance \\
\hline 3 & Moderate importance \\
\hline 5 & Strong importance \\
\hline 7 & The importance is very strong \\
\hline 9 & Extremely powerful importance \\
\hline $2,4,6,8$ & Intermediate value \\
\hline
\end{tabular}

Data collection: The author investigated directly at the social insurance agency of Tien Giang province. In the research sample, the author surveyed the opinions of experts including managers and chief accountants. Time to complete the collection of data from February to April 2020. Total number of votes collected is 12 votes. The number of votes sent directly to experts is 05 . Number of votes collected 05 votes. At the accounting department, 07 votes are collected. The votes had fully answered the contents and there were no conflicting answers. The number of votes to be used is 07 . The author has conducted in-depth interviews with different subjects. Some interviews were conducted independently at the workplaces or at home of the interviewees. The interview time was about 45 minutes to 60 minutes per people.

\section{RESULTS}

\section{A. Calculate the Pair-Wise Matrix}

Set up the matrix comparing the pair of the factor contribution or effect on the criterion of the hierarchy. Half of the comparison matrix is the inverse of the other half. The element on the left-hand side of the matrix is compared with the element in the top row of the matrix (table 5).
TABLE V. MATRIX OF COMPARISON OF PAIRS OF CRITERIA

\begin{tabular}{|l|l|l|l|l|}
\hline \multicolumn{1}{|c|}{ Criteria } & $\begin{array}{c}\text { Salary } \\
\text { policy }\end{array}$ & $\begin{array}{c}\text { Labour and } \\
\text { employment } \\
\text { policy }\end{array}$ & $\begin{array}{c}\text { Staff } \\
\text { qualifications }\end{array}$ & $\begin{array}{c}\text { Inspection and } \\
\text { assessment } \\
\text { work }\end{array}$ \\
\hline Salary policy & 1.00 & 1.38 & 0.76 & 1.20 \\
\hline $\begin{array}{l}\text { Labor and } \\
\text { employment } \\
\text { policy }\end{array}$ & 0.73 & 1.00 & 0.93 & 2.04 \\
\hline $\begin{array}{l}\text { Staff } \\
\text { qualifications }\end{array}$ & 1.32 & 1.07 & 1.00 & 2.18 \\
\hline $\begin{array}{l}\text { Inspection and } \\
\text { assessment work }\end{array}$ & 0.83 & 0.49 & 0.46 & 1.00 \\
\hline Total & $\mathbf{3 . 8 7}$ & $\mathbf{3 . 9 4}$ & $\mathbf{3 . 1 5}$ & $\mathbf{6 . 4 1}$ \\
\hline
\end{tabular}

\section{B. Calculate the Weights for the Criteria}

On the basis of the results of the priority, the study carried out the weight analysis of the factors in the research model, this is an important basis to calculate the consistency index in the following table 6 .

TABLE VI. CRITERIA GROUP WEIGHT MATRIX

\begin{tabular}{|l|l|l|l|l|l|}
\hline \multicolumn{1}{|c|}{ Criteria } & $\begin{array}{c}\text { Salary } \\
\text { policy }\end{array}$ & $\begin{array}{c}\text { Labour and } \\
\text { employment } \\
\text { policy }\end{array}$ & $\begin{array}{r}\text { Staff } \\
\text { qualifications }\end{array}$ & $\begin{array}{c}\text { Inspection } \\
\text { and } \\
\text { assessment } \\
\text { work }\end{array}$ & $\begin{array}{c}\text { Weights } \\
\text { (W) }\end{array}$ \\
\hline Salary policy & 0.26 & 0.35 & 0.24 & 0.19 & 0.25901 \\
\hline $\begin{array}{l}\text { Labor and } \\
\text { employment } \\
\text { policy }\end{array}$ & 0.19 & 0.25 & 0.30 & 0.32 & 0.26349 \\
\hline Staff qualifications & 0.34 & 0.27 & 0.32 & 0.34 & 0.31718 \\
\hline $\begin{array}{l}\text { Inspection and } \\
\text { assessment work }\end{array}$ & 0.21 & 0.12 & 0.15 & 0.16 & 0.16033 \\
\hline Total & $\mathbf{1 . 0 0}$ & $\mathbf{1 . 0 0}$ & $\mathbf{1 . 0 0}$ & $\mathbf{1 . 0 0}$ & $\mathbf{1 . 0 0}$ \\
\hline
\end{tabular}

\section{Evaluating the Research Model}

Determine the consistency vector by dividing the total weight vector by the weights of the previously defined criteria. Calculate the maximum eigenvalue ( $\lambda \max )$ by taking the mean of the consistency vector. The study conducted matrix multiplication compared criteria pairs and the criterion group weight matrix was matrix M1. Construct the matrix M2 (Consistent Vector) by dividing each entry of the matrix M1 by the corresponding entry of the criteria group weight matrix (table 7).

TABLE VII. CONSISTENT Vector MATRIX CALCULATION

\begin{tabular}{|l|l|}
\hline \multicolumn{1}{|c|}{ Matrix (M1) } & Matrix (M2) \\
\hline 1.05571 & 4.07597 \\
\hline 1.07324 & 4.07319 \\
\hline 1.28987 & 4.06672 \\
\hline 0.65122 & 4.06187 \\
\hline
\end{tabular}

$\lambda \max =(4.07597+4.07319+4.06672+4.06187) / 4=$ 4.06944

$\mathrm{CI}=(4.06944-4) /(4-1)=0.02315$

With the number of criteria of 4 , we have $\mathrm{RI}=0.9$, then $\mathrm{CR}$ $=0.02315 / 0.9=0.02572<0.1$, evaluating the criteria of the 
criteria scale, so the weights are consistent. The weights are appropriately identified for use in the study. The weights of the criteria determined by AHP are the important levels in the overall assessment of the factors that influence the management of social insurance collection on the site. Specifically, the weights are applied in the evaluation scale that synthesizes the factors affecting the management of social insurance collection, creating an evaluation score according to the respective 5-level scales.

TABLE VIII. AVERAGE WeIGHT OF EVALUATION OF FACtors

\begin{tabular}{|l|l|}
\hline \multicolumn{1}{|c|}{ Criteria } & \multicolumn{1}{c|}{ Weights } \\
\hline Salary policy & 0.25901 \\
\hline Labor and employment policy & 0.26349 \\
\hline Staff qualifications & 0.31718 \\
\hline $\begin{array}{l}\text { Inspection and assessment } \\
\text { work }\end{array}$ & 0.16033 \\
\hline
\end{tabular}

Differ from other previous studies (table 8), the result shows a differentiation in the importance of the system of evaluation criteria factors affecting social insurance collection management. The criteria are arranged according to the degree of priority from high to low as follows: Qualification of staff in charge of social insurance collection management, Labour and employment policy, Salary policy, Inspection, and inspection work. Currently, the law of social insurance has the lowest priority in the criteria system with weights ranging from 0.1603 .

The above results show the priorities of the evaluation criteria factors affecting the management of social insurance collection. Criteria Qualification of staff in charge of social insurance collection management, Labour and employment policy, Salary policy is always considered as the top criteria in assessing the factors affecting the management of social insurance collection both in terms of management. Commentary and practice. Inspection and assessment impact the management of social insurance collection. In fact, factors affecting key social insurance collection management such as Salary policy, Labour and employment policy are suitable because they directly affect social insurance payers and employers in the area thus directly affect the collection of social insurance.

\section{CONCLUSION}

This study has provided evidence on the application of AHP in decision-making in the management of social insurance and health insurance collection at the local social insurance agency. The results show the differentiation in the importance of the system of evaluation criteria factors affecting social insurance collection management. The criteria are arranged according to the degree of priority from high to low as follows: Qualification of staff in charge of social insurance collection management, Labour and employment policy, Salary policy, Inspection, and assessment work on current law of social insurance. These are practical implications that meet the expectations of experts and the board of directors. On the basis of the target of social insurance collection, the study proposes solutions and recommendations to contribute to improving efficiency managing closely with the real situation at the social insurance agency including: Strengthening measures to manage and develop social insurance revenues; Overcoming outstanding debts, evading social insurance contributions; Administrative reform in social insurance collection management; Strengthen the inspection process; Associate penalties with timely rewards. The AHP model can provide the consistency of the decision-making process. Moreover, the hierarchical analysis process considers many criteria and analyses both qualitative and quantitative factors. Therefore, the further direction of research is to combine AHP with other methods to take advantage of each method in problem solving.

\section{REFERENCES}

[1] Z. Ansari, M.I. Tabash, A. Akhtar, S.H. Khan and E.M. Al-Matari, "Identifying and ranking the driving forces of social insurance by analytical hierarchy process: evidence from India," Heliyon, vol. 5, no. (10), pp. e02683, 2019.

[2] G. Andreas and D. Anastasion, "Social Security Rate for Companies," Trading Economics, Journal of Money, Investment and Banking, 2013.

[3] Nguyễn Xuân Cường and Nguyễn Xuân Thọ và Hồ Huy Tựu, “A number of factors affect the interest in social insurance of small retailers in Nghe An province," Science magazine Ha Noi national university, vol. 30, no. (1), pp. 36-45, 2014.

[4] Trần Công Dũng, "Some problems with the choice and connectivity of social insurance," Journal of Social Insurance, vol. 1. pp. 35, 2017.

[5] N. Van Sinh, T.M. Ha and N.T. Thanh, "Filling holes on the surface of 3D point clouds based on tangent plane of hole boundary points," Proceedings of the Seventh Symposium on Information and Communication Technology, pp. 331-338, 2016.

[6] T.L. Saaty and L.G. Vargas, "Estimating technological coefficients by the analytic hierarchy process," Socio-Economic Planning Sciences, vol. 13, no. (6), pp. 333-336, 1979.

[7] T.H. Pham, T.B. Mac, V.C. Tong, T.L. Banh and D.T. Nguyen, "Simulation and experimental studies to verify the effect of cutting parameters on chip shrinkage coefficient and cutting forces in machining of A6061 aluminum alloy," Advances in Mechanical Engineering, vol. 8, no. (10), pp. $1687814016673297,2016$. 